Article

\title{
Do Older Adults with Multimorbidity Meet the Recommended Levels of Physical Activity? An Analysis of Scottish Health Survey
}

\author{
Ahmad Salman ${ }^{1,2, *(1)}$ and Maha Sellami ${ }^{3}$ (I) \\ 1 Department of Public Health, College of Health Sciences, QU Health, Qatar University, Doha 2713, Qatar \\ 2 Department of Health Sciences, University of York, Heslington, York YO10 5DD, UK \\ 3 Sport Science Program (SSP), College of Arts and Sciences (CAS), Qatar University, Doha 2713, Qatar; \\ msellami@qu.edu.qa \\ * Correspondence: as1816@york.ac.uk
}

Received: 21 August 2019; Accepted: 30 September 2019; Published: 4 October 2019

\begin{abstract}
There is a positive association between physical activity (PA) and improved health in older adults. The objective of this study was to assess the prevalence and determinants of meeting recommended levels of PA among older adults with multimorbidity. Data has been derived from the nationally representative Scottish Health Surveys (2014-2017). A sub-sample of 2230 older adults (aged 65+) with multimorbidity were the study participants. Physical activity was evaluated using current recommended guidelines. Overall, $32.3 \%$ of the participants met the recommended levels of PA. Independent predictors of meeting the recommended levels of PA include male gender [odds ratio (OR) 2.00 (95\% confidence interval (CI) 1.58-2.54)], living in the least deprived areas [OR 1.79 (95\% CI 1.20-2.69)]; being a non-smoker [OR 2.22 (95\% CI 1.48-3. 34)]. Also, meeting recommended PA decreased with age [OR 0.92 (95\% CI 0.90-0.94)] and body mass index [OR 0.93 (95\% CI 0.91-0.95]; but increased per additional portion of fruit and vegetables taken [OR 1.19 (95\% CI 1.12-1.25)] and with increase in well-being scale score [OR 1.05 (95\% CI 1.03 to 1.06)]. Adherence to PA guidelines seems to be more related to age, BMI, gender (i.e. higher PA adherence in men vs. women), social support (i.e. social deprivation), dietary habits (i.e. fruit and vegetable intake) and social isolation among the elderly. In the one-third of older population, adherence to PA was associated to better mental health. Therefore, adaptation of PA guideline to suit theses determinants factors would reduce the gap difference among older adults with multimorbidity and enhance their mental well-being.
\end{abstract}

Keywords: physical activity; multimorbidity; older adults

\section{Introduction}

Globally, the average life expectancy is increasing over the last three decades [1]. This has led to a rise in the number of people living with chronic diseases or health conditions and the number of years lived with disability [1,2]. Multimorbidity would seem a relatively straightforward term, denoting the co-existence of two or more chronic health conditions in an individual and it is now an important global challenge [3]. A meta-analysis involving over 7 million primary care patients in 12 countries found that the prevalence of multimorbidity ranged from 12.9 to $95.1 \%$ [4]. Also, a survey in the United Kingdom has shown that multimorbidity accounts for one-third of all consultations in general practice [5]. The World Health Survey carried out between 2002 and 2004 showed that about $50 \%$ of middle-aged adults (i.e. 50-64 years) to elderly (i.e. $\geq 65$ years) category have multimorbidity with two or more chronic medical conditions, about a quarter have at least three, and one tenth have four or more chronic medical conditions [6]. Multimorbidity is associated with socioeconomic decline, 
higher health care utilization and increased risk of poor mental well-being [3-5,7]. It has been shown to predict future functional decline, with higher decline in individuals with a higher number of chronic conditions and increased disease severity [7].

Healthy behavior such as physical activity (PA) has been shown to be an important determinant in the management of chronic medical conditions and for the improvement of life expectancy $[8,9]$. Adherence to recommended PA has been identified as a means of primary and secondary prevention of several chronic diseases such as cardiovascular diseases, diabetes mellitus and cancer [10]. Also, PA has been shown to improve quality of life [11], and it is associated with a $22 \%$ reduction in the risk of premature mortality among older adults [12]. Adherence to World Health Organization (WHO) minimum PA levels (i.e. $150 \mathrm{~min} /$ week), is associated with a $10 \%$ reduction in all-cause mortality, and the WHO estimates that about 3.2 million deaths annually are attributable to physical inactivity $[13,14]$. Recent studies in several countries have demonstrated that adherence to recommended levels of PA is associated with a significant reduction in chronic diseases risk among adult males and females, and even the practice of once weekly vigorous PA is sufficient to lower the risks of chronic diseases [14-16].

Given the benefits on the risk of chronic conditions, the promotion of PA is now considered an essential strategy within the multifaceted care of multimorbidity in the elderly. Studies examining the association between the occurrence of multimorbidity and PA has shown dissenting results with some studies demonstrating an inverse association $[17,18]$ and others reporting no relationship $[19,20]$. However, one recent multinational study demonstrated that there is a $31 \%$ increased risk of multimorbidity among individuals with low PA [6]. Also, a longitudinal study evaluating the burden of multimorbidity over time by levels of PA in elderly English population demonstrated an inverse dose-response relationship with the odds of multimorbidity being lower in those who were physically active than those who were not [21]. Limitations in PA and function due to multimorbidity can substantially affect the treatment burden and response to care among affected individuals, which may further increase multimorbidity [22]. Given the bidirectional interplay between PA and multimorbidity, at the population level, there is limited information on adherence to recommended levels of PA in individuals with multimorbidity and the associated factors. Such information could guide the design and delivery of targeted interventions. We aimed to investigate the prevalence and determinants of meeting recommended levels of PA among older adults with multimorbidity in a Scottish population.

\section{Materials and Methods}

\subsection{Study Design and Participants}

The analysis is based on a data collected as part of the Scottish Health Survey (SHeS) which is a periodic cross-sectional nationally representative survey commissioned by the Scottish Government Health Directorates [23]. The SHeS was designed to provide comprehensive information about the health and factors related to health of the Scottish population. Further details of the survey's methods and questionnaire can be found the SHeS website: www.gov.scot/scottishhealthsurvey.

For the purpose of this study, we included data on adults aged 65 and older from SHeS surveys carried out annually between 2014 and 2017 by ScotCen Social Research-Edinburgh, MRC/CSO Social and Public Health Sciences Unit-Glasgow, the Centre for Population Health Sciences- University of Edinburgh and the Public Health Nutrition Research Group-Aberdeen University. This observational study was reported following the guidelines of the Strengthening the Reporting of Observational Studies in Epidemiology (STROBE).

\subsection{Measures}

All participants completed an interviewer-administered questionnaire by trained interviewer. The interview covers anthropometric, longstanding illness, deprivation, smoking, mental health, fruit and vegetable consumption and PA. 
Participants were asked about a number of specific health conditions, including doctor- diagnosed diabetes or doctor-diagnosed hypertension and if they had any physical or mental health condition or illness lasting - or likely to last - for twelve months or more [24]. Those who reported having such a condition were asked to provide details of the type(s) of conditions or illnesses reported. For the purpose of this study, we restricted our analysis only to individuals with multimorbidity. Individuals were classified as 'with multimorbidity' if they reported two or more longstanding illness. Fruit and vegetable consumption were assessed with the intention to monitor population-level adherence to the five-a-day recommendation. Smoking status was classified into 'current cigarette smoker', 'ex-cigarette smoker' and 'never smoked cigarettes at all'. The area deprivation data are presented in Scottish Index of Multiple Deprivation (SIMD) quintiles. Mental well-being was measured using the Warwick-Edinburgh Mental Well-being Scale (WEMWBS) questionnaire [25].

\subsection{Physical Activity}

Physical activity interview module questions were based on the Allied Dunbar National Fitness Survey [24]. Participants were asked to report any activities that lasted at least 10 minutes and the number of days in the past four weeks in which they had taken part in such activities. The interview questions consisted of four main types of physical activity: home-based activities (housework, gardening, building work and DIY), walking, sports and exercise, and activity at work. The information was collected based on time spent being active, intensity of the activities undertaken, and frequencies with which activities are performed. The intensity level of activities mentioned by participants was estimated to help assess adherence to this guideline. A more detailed discussion of estimation of the amount of PA is provided in the SHeS report [24]. Physical activity was classified into 'Met' and 'Unmet' based on Moderate or Vigorous PA (MVPA) guidelines on the recommended amounts of PA for adults, issued by the UK Chief Medical Officer in 2011 [26]. Current guidelines in the UK recommends that adults need to undertake 150 minutes of moderate PA per week or 75 minutes of vigorous activity per week or an equivalent combination of both [24]. This is the recommended level of PA referred to throughout this paper.

\subsection{Ethical Considerations}

The SHeS data were analysed with the permission of the UK Data Service [23]. The cross-sectional surveys data are freely available for academic researchers to download from the UK Data Service. Participants gave informed consent for data linkage for future research data analysis

\subsection{Statistical Data Analysis}

The data analysis in this study was performed with IBM Statistical Package and Services Solutions (SPSS) software version 25 (IBM Corp, Armonk, New York, USA). A p value $\leq 0.05$ was considered statistically significant. Categorical variables were summarized as proportion and continuous variables were reported as mean (SD: standard deviation). The main outcome variable was meeting the recommended PA. A univariate analysis was first performed to determine the association between the outcome variable and potential predictor variables. The $t$ test (or where appropriate ANOVA) was used to compare continuous variables. Logistic regression analysis was performed to assess the association between meeting recommended PA in older adults with sociodemographic and clinical factors and including all variables with univariate $p=0.1$ or lower to determine the independent predictors of the outcome variable. Model fit was assessed using the likelihood ratio test. The area under the ROC curve was $0.74,95 \% \mathrm{CI}[0.71,0.77]$, which is an acceptable level of discrimination according to Hosmer et al. [26]. The logistic regression model was statistically significant $\left(\chi^{2}(11)=258.80, p<0.0001\right)$, explained $21.8 \%$ (Nagelkerke R2) of variance in meeting recommended PA, and correctly classified $69.9 \%$ of cases. Sensitivity was $49.6 \%$, specificity $82.7 \%$, positive predictive value $64.3 \%$, and negative predictive value $72.3 \%$. 


\section{Results}

Of the total 5106 adults aged 65 years and over [2287 men (44.8\%) and 2819 women (55.2\%)], who participated in the 2014-2017 period, total numbers of valid samples that have been used in this analysis were 2230 who have two or more morbidities. The morbidity profile of the participants is summarized in Table 1. The commonest morbidities among the participants were arthritis (36.6\%), hypertension $(30.0 \%)$ and diabetes $(18.8 \%)$. To assess the model for influential cases, Cook's distance test and leverage values were computed but neither test produced unusually high values $(p<1.00$ for all). The Hosmer-Lemeshow test in the final model was not statistically significant $(p=0.56)$, indicating that the model is not a poor fit.

Table 1. Morbidities profile of older adults with multimorbidity.

\begin{tabular}{cccc}
\hline Characteristics & \% (N) & Male \% & Female \% \\
\hline Cancer & $9.1 \%(204)$ & $48 \%$ & $52 \%$ \\
Diabetes & $18.8 \%(420)$ & $49.3 \%$ & $50.7 \%$ \\
Mental disorders & $8 \%(179)$ & $37.4 \%$ & $62.6 \%$ \\
Stroke & $3.8 \%(85)$ & $37.6 \%$ & $62.4 \%$ \\
Ischaemic heart disease/Heart attack/angina & $12.6 \%(280)$ & $45.7 \%$ & $54.3 \%$ \\
Hypertension & $30 \%(670)$ & $43 \%$ & $57 \%$ \\
COPD & $9 \%(201)$ & $49.8 \%$ & $50.2 \%$ \\
Asthma & $9.2 \%(205)$ & $35.1 \%$ & $64.9 \%$ \\
Arthritis/rheumatism/fibrositis & $36.6 \%(817)$ & $33.8 \%$ & $66.2 \%$ \\
Back problems/slipped disc/spine/neck & $11.6 \%(259)$ & $44.8 \%$ & $55.2 \%$ \\
\hline COPD
\end{tabular}

The characteristics of the participants are summarized in Table 2. Mean age of the participants was 74.54 (6.87) years and their mean body mass index (BMI) was $29.29(5.53) \mathrm{kg} / \mathrm{m}^{2}$. Overall, 32.3\% of the participants met the recommended levels of PA, and $18.3 \%$ were in the most-deprived quintile. Also, $12.4 \%$ of them were current smokers. The average total portion of fruit and vegetable intake per participant was 3.12 (2.18) portions.

Table 2. Demographics and health states of older adults with multimorbidity.

\begin{tabular}{cccc}
\hline \multicolumn{1}{c}{ Characteristics } & & Male & Female \\
\hline \multirow{2}{*}{ PA meeting recommendations } & Met $(32.3 \%)$ & $52.3 \%$ & $47.7 \%$ \\
& Unmet $(67.7 \%)$ & $37.9 \%$ & $62.1 \%$ \\
\hline \multirow{2}{*}{ SIMD quintiles } & Least deprived (17.4\%) & $43.3 \%$ & $56.7 \%$ \\
& $4(19.2 \%)$ & $42.8 \%$ & $57.2 \%$ \\
& $3(23.5 \%)$ & $43.9 \%$ & $56.1 \%$ \\
& $2(21.6 \%)$ & $42.7 \%$ & $57.3 \%$ \\
& Most deprived (18.3\%) & $40 \%$ & $60 \%$ \\
\hline \multirow{2}{*}{ Cigarette smoking status } & Never smoked (44.5\%) & $32.2 \%$ & $67.8 \%$ \\
& Ex-smoker (43.1\%) & $52.2 \%$ & $47.8 \%$ \\
& Current smoker (12.4\%) & $46.6 \%$ & $53.4 \%$ \\
\hline Mean (SD) Age & $74.54(6.87)$ & $74.13(6.62)$ & $74.85(7.04)$ \\
\hline Mean (SD) BMI & $29.29(5.53)$ & $29.58(5.25)$ & $29.07(5.73)$ \\
\hline Mean (SD) portion of fruit and vegetable & $3.12(2.18)$ & $3.11(2.21)$ & $3.13(2.17)$ \\
\hline Mean (SD) WEMWBS score & $49.06(8.48)$ & $48.79(8.58)$ & $49.26(8.41)$ \\
\hline
\end{tabular}

BMI, body mass index; PA, Physical activity; SD, standard deviation; SIMD, Scottish Index of Multiple Deprivation; WEMWBS, Warwick-Edinburgh Mental Well-being Scale.

The differences in the participants meeting the recommended PA according to their demographic characteristics are summarized in Tables 3 and 4 . The proportion of current smoker among those meeting 
and not meeting the recommended PA levels was $(9.1 \%$ vs. $14.1 \% ; P<0.05)$. Also, there was a progressive increase in the proportion of deprivation among participants not meeting the recommended PA level $(p<0.05)$. The mean total portion of fruit and vegetable intake per week among participants meeting and not meeting the recommended PA level were $(3.81 \pm 2.30$ vs. $2.80 \pm 2.05 ; p<0.05)$. The mean age $(72.28 \pm 5.87$ vs. $75.64 \pm 7.06$ years; $p<0.05)$ and BMI $\left(28.63 \pm 4.61\right.$ vs. $\left.29.68 \pm 5.98 \mathrm{~kg} / \mathrm{m}^{2} ; p<0.05\right)$ of the participants meeting the recommended PA level was significantly lower than those not meeting the recommended PA level. However, there was a significantly higher mean WEMWBS score among participants meeting the recommended level of PA $(51.66 \pm 7.95$ vs. $47.67 \pm 8.42 ; p<0.05)$.

Table 3. Difference of categories variables between groups.

\begin{tabular}{cccc}
\hline Characteristics & & Meeting PA Group \% & Unmet PA Group \% \\
\hline \multirow{2}{*}{ Cigarette Smoking Status * } & Never smoker & $48.3 \%$ & $42.7 \%$ \\
& Ex-smoker & $42.7 \%$ & $43.2 \%$ \\
& Current smoker & $9.1 \%$ & $14.1 \%$ \\
\hline \multirow{2}{*}{ SIMD * } & Least deprived & $22.3 \%$ & $15 \%$ \\
& 4 & $23.4 \%$ & $17.3 \%$ \\
& 3 & $22.7 \%$ & $23.8 \%$ \\
& 2 & $18.3 \%$ & $23.2 \%$ \\
& Most deprived & $13.2 \%$ & $20.7 \%$ \\
\hline
\end{tabular}

PA, physical activity; SIMD, Scottish Index of Multiple Deprivation; ${ }^{*} p \leq 0.05$.

Table 4. Difference of continuous variables among groups.

\begin{tabular}{ccc}
\hline Characteristics & $\begin{array}{c}\text { Meeting PA Group; } \\
\text { Mean (SD) }\end{array}$ & $\begin{array}{c}\text { Unmet PA Group; } \\
\text { Mean (SD) }\end{array}$ \\
\hline Age * $_{\text {BMI * }}$ & $72.28(5.87)$ & $75.64(7.06)$ \\
Total portion of fruit and vegetables * & $28.63(4.61)$ & $29.68(5.98)$ \\
WEMWBS score * & $3.81(2.30)$ & $2.80(2.05)$ \\
& $51.66(7.95)$ & $47.67(8.42)$ \\
\hline
\end{tabular}

BMI, body mass index; PA, Physical activity; SD, standard deviation; WEMWBS, Warwick-Edinburgh Mental Well-being Scale; ${ }^{*} p \leq 0.05$.

A binomial logistic regression was performed to ascertain sociodemographic and clinical factors associated with meeting recommended PA in older adults with multiple comorbidities (Table 5). The probability of meeting recommended PA was 100\% higher (odds ratio (OR) 2.00 (95\% CI 1.58 to 2.54 )) for male than female; 79\% higher (OR 1.79 (95\% CI 1.20 to 2.69) for those living in the least deprived areas than among those in the most deprived areas; $122 \%$ higher (OR 2.22 (95\% CI 1.48 to 3.34) for never smoked at all or never regular smoker than current smoker.

The probability of meeting recommended PA decreased by 8\% (OR 0.92 (95\% CI 0.90 to 0.94)) per additional year and by $7 \%$ (OR 0.93, 95\% CI 0.91 to 0.95$)$ per 1-point increase in BMI.

The probability of meeting recommended PA increased by 19\% (OR 1.19 (95\% CI 1.12 to 1.25)) per additional portion of fruit and vegetables and by 5\% (OR 1.05, 95\% CI 1.03 to 1.06) per 1-point increase in WEMWBS score. 
Table 5. Full details on binomial logistic regression.

\begin{tabular}{ccccccccc}
\hline & $\mathbf{B}$ & $\mathbf{S E}$ & Wald & $\mathbf{d f}$ & $\mathbf{p}$ & OR & \multicolumn{2}{c}{$\mathbf{9 5 \%}$ CI for OR } \\
\cline { 6 - 9 } & & & & & & Lower & Upper \\
Gender (Male) & $\mathbf{0 . 6 9}$ & $\mathbf{0 . 1 2}$ & $\mathbf{3 2 . 9 2}$ & $\mathbf{1 . 0 0}$ & $\mathbf{0 . 0 0 0}$ & $\mathbf{2 . 0 0}$ & $\mathbf{1 . 5 8}$ & $\mathbf{2 . 5 4}$ \\
\hline SIMD (least deprived) & 0.58 & 0.21 & 7.96 & 1.00 & $0.005^{*}$ & 1.79 & 1.20 & 2.69 \\
SIMD (4) & 0.66 & 0.20 & 10.88 & 1.00 & $0.001^{*}$ & 1.94 & 1.31 & 2.88 \\
SIMD (3) & 0.29 & 0.20 & 2.17 & 1.00 & 0.140 & 1.33 & 0.91 & 1.96 \\
SIMD (2) & 0.54 & 0.20 & 7.14 & 1.00 & $0.008^{*}$ & 1.72 & 1.15 & 2.55 \\
Age & & & 14.35 & 4.00 & $0.006^{*}$ & & & \\
SIMD (most deprived as reference) & -0.09 & 0.01 & 72.12 & 1.00 & $0.000^{*}$ & 0.92 & 0.90 & 0.94 \\
Smoking status (never smoker) & 0.80 & 0.21 & 14.65 & 1.00 & $0.000^{*}$ & 2.22 & 1.48 & 3.34 \\
Smoking status (ex-regular smoker) & 0.54 & 0.21 & 6.95 & 1.00 & $0.008^{*}$ & 1.72 & 1.15 & 2.59 \\
Smoking status (current smoker as reference) & & & 15.30 & 2.00 & $0.000^{*}$ & & & \\
Total portion of fruit and vegetables & 0.17 & 0.03 & 35.81 & 1.00 & $0.000^{*}$ & 1.19 & 1.12 & 1.25 \\
BMI & -0.07 & 0.01 & 34.80 & 1.00 & $0.000^{*}$ & 0.93 & 0.91 & 0.95 \\
WEMWBS score & 0.05 & 0.01 & 38.09 & 1.00 & $0.000^{*}$ & 1.05 & 1.03 & 1.06 \\
Constant & 3.79 & 0.94 & 16.36 & 1.00 & $0.000^{*}$ & 44.10 & & \\
\hline
\end{tabular}

$\mathrm{B}=$ unstandardised regression coefficient; $\mathrm{BMI}$, body mass index; $\mathrm{CI}=$ Confidence Interval for odds ratio; $\mathrm{df}$, degrees of freedom; OR, odds ratio. S.E.; standard error of the coefficient; SIMD, Scottish Index of Multiple Deprivation; WEMWBS, Warwick-Edinburgh Mental Well-being Scale; * $p \leq 0.05$.

\section{Discussion}

The current study aimed to assess the prevalence and determinants of meeting recommended PA level among Scottish older adults with multimorbidity. The findings of the study showed that about one-third of the study population were adherent to the recommended PA levels, and a slightly higher proportion of men than women met the recommended level of PA. The independent predictors of meeting recommended PA levels were male gender, living in less-deprived areas, being a non- or ex-smoker, having lower BMI, higher fruit and vegetables intake and higher WEMWBS score. Together, the findings of this study suggest that there are opportunities for a health promotion intervention to modify the lifestyle of Scottish older adults towards improving the outcomes of their co-morbid chronic medical conditions.

Despite the substantial evidence on the inverse relationships between PA and the risk of development or worsening of the cardiovascular diseases [27-29], we found that less than a third of the study population with multimorbidity met the recommended PA level. This high nonadherence to recommended PA will most likely predispose them to either worsening of the multimorbidity or have poor management outcomes. In this study, we found that belonging to the less-deprived socioeconomic groups was an independent predictor of meeting the recommended level of PA among older adults with multimorbidity surveyed. Our finding is consistent with the results of several studies, reviews and their umbrella review which showed that older adults with higher socioeconomic status are more likely to undertake PA compared with those belonging to the lower socioeconomic group [30-33]. This suggests that improving the socioeconomic status of the elderly in this setting may improve their likelihood of adopting healthy behaviours like PA. A cohort study in Germany showed that older adults with high social support are more likely to undertake PA compared with those with low social support [31].

In this study, we found that non-modifiable factors like age and gender were also predictors of PA in the elderly with multimorbidity. We found that there was an inverse association between age and PA. This suggests that even among the elderly, the older they become the less likely they may meet the recommended level of PA. Possible reasons may be that most elderly individuals are prone to substantial disability, gait disorder and falls during late life leading to activity restriction [33,34]. Also, we found that male participants were twice more likely to meet the recommended PA levels compared with females. Previous studies have documented gender differences in the levels of PA among the elderly with men significantly more likely to engage in sporting activities and women significantly more likely to engage in domestic activities [35-37]. 
Being a non- or an ex-smoker was an independent predictor of meeting the recommended level of PA in this study. This suggests that not smoking or smoking cessation potentially has other health benefits. Previous studies among older adults on the relation between smoking and PA have provided mixed findings; while majority of the studies found that there was a significant relationship between being a non- or an ex-smoker and higher PA [38,39], a few found no relationship between smoking and PA [31]. The differences between these studies deserve further investigation. Furthermore, a previous study has shown that overweight and obese individuals with low PA had a higher cardiovascular disease risk than normal weight participants with high PA [40]. This underscores the importance of PA in health outcomes of older adults with multimorbidity. In this study, we found an inverse association between BMI and physical activity. This is consistent with previous studies and suggest the need for weight reduction among individuals with multimorbidity [41,42]. Also, we found that higher fruits and vegetable consumption was associated with meeting recommended PA. This is consistent with previous studies that showed that higher fruits and vegetable consumption was associated with good self-rated health and the likelihood to engage in healthy behaviours [43,44].

This study also showed that having a higher degree of mental well-being was a predictor of meeting recommended PA among older adults with multimorbidity. This finding adds to the growing body of evidence on the relationship between mental well-being and PA. Several studies have shown that there is a direct relationship between PA and mental well-being in the elderly [45-47]. A study in the United States found that light physical activities were positively associated with mental health and life satisfaction in summer [45]. However, engaging in moderate physical activities was positively related only with physical health [44]. Other population-based studies showed a consistent association between enhanced psychological well-being, as measured using a variety of psychological inventories, and regular physical exercise [46,47]. Our study indicates that there is likelihood of a bidirectional relationship between PA and mental well-being. Physical activity and especially moderate intensive aerobic exercise is shown to be accompanied by higher benefits in well-being and mood [48], and quality of life [49]. In the elderly, these activities that require oxygen (brisk walking, running, swimming) also allow them to build their brains [50]. In this study researchers explain that two sessions a week could prevent age-related neurological decline and even strengthen the memory of older people. The aerobic exercise for 70 to $80 \%$ of the maximum cardiac capacity promote oxygen flow to the muscles, it helps to work the heart and lungs.

This study has the following strengths. First, it was based on data from the elderly with multimorbidity complemented by self-reported assessment of PA and mental well-being. Second, it was based on data from large, nationally representative surveys designed to measure health status at the population level. However, the study has some limitations. All analyses performed were cross-sectional and causal inferences should not be made. Second, some of the information collected during the survey may be limited by recall bias. Third, some of the assessment made e.g. the relationship between PA and mental well-being is likely to be moderated by seasonal variations [43]. We did not adjust for the effect of season in our regression model. Further research should consider adjusting for additional indicators such as social support, season, dietary habits and social isolation among the elderly.

\section{Conclusions}

About one-third of older Scottish population with multimorbidity had recommended PA levels, with a slight male preponderance. Being male, living in less-deprived areas, being a non- or ex-smoker, having lower BMI, have higher fruit and vegetables intake and higher mental well-being score were determinants of meeting recommended PA in the study setting. Multi-level and multi-component interventions targeting the identified determinants are needed to increase PA in the older adults with multimorbidity in the study setting. 
Author Contributions: Conceptualization, A.S.; Formal analysis, A.S.; Investigation, A.S.; Methodology, A.S.; Validation, A.S. and M.S.; Visualization, A.S.; Writing—original draft, A.S.; Writing-review \& editing, A.S. and M.S.

Funding: This research received no specific grant from any funding agency in the public, commercial, or not-forprofit sectors. The Scottish Health Survey is funded by the Scottish Executive. The funders had no role in the present study.

Acknowledgments: The publication of this article was funded by the Qatar National Library.

Conflicts of Interest: The authors declare no conflicts of interest.

\section{References}

1. Dicker, D.; Nguyen, G.; Abate, D.; Abate, K.H.; Abay, S.M.; Abbafati, C.; Abbasi, N.; Abbastabar, H.; Abd-Allah, F.; Abdela, J.; et al. Global, regional, and national age-sex-specific mortality and life expectancy, 1950-2017: A systematic analysis for the Global Burden of Disease Study 2017. Lancet 2018, 392, 1684-1735. [CrossRef]

2. James, S.L.; Abate, D.; Abate, K.H.; Abay, S.M.; Abbafati, C.; Abbasi, N.; Abbastabar, H.; Abd-Allah, F.; Abdela, J.; Abdelalim, A.; et al. Global, regional, and national incidence, prevalence, and years lived with disability for 354 diseases and injuries for 195 countries and territories, 1990-2017: A systematic analysis for the Global Burden of Disease Study 2017. Lancet 2018, 392, 1789-1858. [CrossRef]

3. Smith, S.M.; Wallace, E.; O'Dowd, T.; Fortin, M. Interventions for improving outcomes in patients with multimorbidity in primary care and community settings (Review). Cochrane Database Syst. Rev. 2016, CD006560. [CrossRef]

4. Violan, C.; Foguet-Boreu, Q.; Flores-Mateo, G.; Salisbury, C.; Blom, J.; Freitag, M.; Glynn, L.; Muth, C.; Valderas, J.M. Prevalence, Determinants and Patterns of Multimorbidity in Primary Care: A Systematic Review of Observational Studies. PLoS ONE 2014, 9, e102149. [CrossRef]

5. Salisbury, C.; Johnson, L.; Purdy, S.; Valderas, J.M.; Montgomery, A.A. Epidemiology and impact of multimorbidity in primary care: A retrospective cohort study. Br. J. Gen. Pract. 2011, 61, e12-e21. [CrossRef] [PubMed]

6. Vancampfort, D.; Koyanagi, A.; Ward, P.B.; Rosenbaum, S.; Schuch, F.B.; Mugisha, J.; Richards, J.; Firth, J.; Stubbs, B. Chronic physical conditions, multimorbidity and physical activity across 46 lowand middle-income countries. Int. J. Behav. Nutr. Phys. Act. 2017, 14, 1-13. [CrossRef] [PubMed]

7. Ryan, A.; Wallace, E.; O'Hara, P.; Smith, S.M. Multimorbidity and functional decline in community-dwelling adults: A systematic review. Health Qual. Life Outcomes 2015, 13, 1-13. [CrossRef]

8. Li, Y.; Pan, A.; Wang, D.D.; Liu, X.; Dhana, K.; Franco, O.H.; Kaptoge, S.; Di Angelantonio, E.; Stampfer, M.; Willett, W.C.; et al. The Impact of Healthy Lifestyle Factors on Life Expectancies in the US population. Circulation 2018, 138, 345-355. [CrossRef]

9. Martinez-Gomez, D.; Guallar-Castillon, P.; Garcia-Esquinas, E.; Bandinelli, S.; Rodríguez-Artalejo, F. Physical Activity and the Effect of Multimorbidity on All-Cause Mortality in Older Adults. Mayo Clin. Proc. 2017, 92, 376-382. [CrossRef]

10. Pedersen, B.K.; Saltin, B. Exercise as medicine-Evidence for prescribing exercise as therapy in 26 different chronic diseases. Scand. J. Med. Sci. Sports 2015, 25, 1-72. [CrossRef]

11. Bertheussen, G.F.; Romundstad, P.R.; Landmark, T.; Kaasa, S.; Dale, O.; Helbostad, J.L. Associations between Physical Activity and Physical and Mental Health-A HUNT 3 Study. Med. Sci. Sports Exerc. 2011, 43, 1220-1228. [CrossRef] [PubMed]

12. Hupin, D.; Roche, F.; Gremeaux, V.; Chatard, J.C.; Oriol, M.; Gaspoz, J.M.; Barthélémy, J.C.; Edouard, P. Even a low-dose of moderate-to-vigorous physical activity reduces mortality by $22 \%$ in adults aged $\geq 60$ years: A systematic review and meta-analysis. Br. J. Sports Med. 2015, 49, 1262-1267. [CrossRef] [PubMed]

13. Kelly, P.; Kahlmeier, S.; Götschi, T.; Orsini, N.; Richards, J.; Roberts, N.; Scarborough, P.; Foster, C. Systematic review and meta-analysis of reduction in all-cause mortality from walking and cycling and shape of dose response relationship. Int. J. Behav. Nutr. Phys. Act. 2014, 11, 1-15. [CrossRef] [PubMed]

14. World Health Organisation. Global Recommendations on Physical Activity for Health; World Health Organisation: Geneva, Switzerland, 2010. 
15. Marques, A.; Peralta, M.; Sarmento, H.; Martins, J.; González Valeiro, M. Associations between vigorous physical activity and chronic diseases in older adults: A study in 13 European countries. Eur. J. Public Health 2018, 28, 950-955. [CrossRef] [PubMed]

16. Ryan, A.; Murphy, C.; Boland, F.; Galvin, R.; Smith, S.M. What is the impact of physical activity and physical function on the development of multimorbidity in older adults over time? A population-based cohort study. J. Gerontol. Ser. A Biol. Sci. Med. Sci. 2018, 73, 1538-1544. [CrossRef] [PubMed]

17. Autenrieth, C.S.; Kirchberger, I.; Heier, M.; Zimmermann, A.K.; Peters, A.; Döring, A.; Thorand, B. Physical activity is inversely associated with multimorbidity in elderly men: Results from the KORA-Age Augsburg Study. Prev. Med. 2013, 57, 17-19. [CrossRef] [PubMed]

18. Cimarras-Otal, C.; Calderón-Larrañaga, A.; Poblador-Plou, B.; González-Rubio, F.; Gimeno-Feliu, L.A.; Arjol-Serrano, J.L.; Prados-Torres, A. Association between physical activity, multimorbidity, self-rated health and functional limitation in the Spanish population. BMC Public Health 2014, 14, 1-10. [CrossRef]

19. Hudon, C.; Soubhi, H.; Fortin, M. Relationship between multimorbidity and physical activity: Secondary analysis from the Quebec health survey. BMC Public Health 2008, 8, 1-8. [CrossRef] [PubMed]

20. Fortin, M.; Haggerty, J.; Almirall, J.; Bouhali, T.; Sasseville, M.; Lemieux, M. Lifestyle factors and multimorbidity: A cross sectional study. BMC Public Health 2014, 14, 1-8. [CrossRef]

21. Dhalwani, N.N.; O’Donovan, G.; Zaccardi, F.; Hamer, M.; Yates, T.; Davies, M.; Khunti, K. Long terms trends of multimorbidity and association with physical activity in older English population. Int. J. Behav. Nutr. Phys. Act. 2016, 13, 1-9. [CrossRef]

22. Calderón-Larrañaga, A.; Vetrano, D.L.; Ferrucci, L.; Mercer, S.W.; Marengoni, A.; Onder, G.; Eriksdotter, M.; Fratiglioni, L. Multimorbidity and functional impairment-bidirectional interplay, synergistic effects and common pathways. J. Intern. Med. 2019, 285, 255-271. [CrossRef] [PubMed]

23. ScotCen Social Research. Scottish Health Survey, 2017; Data Collection; UK Data Service: Colchester, UK, 2019.

24. Bardsley, D.; Dean, L.; Dougall, I.; Feng, Q.; Gray, L.; Karikoski, M.; Rose, J.; Stevens, C.; Leyland, A.H. Scottish Health Survey 2017: Volume One-Main Report; McLean, J., Christie, S., Hinchliffe, S., Gray, L., Eds.; ScotCen Social Research: Edinburgh, UK, 2018; Volume 1.

25. NHS Health Scotland Mental Health and Well-being. Available online: http://www.healthscotland.scot/ health-topics/mental-health-and-well-being/wemwbs (accessed on 22 June 2019).

26. Department of Health and Social Care UK Physical Activity Guidelines. Available online: https://www.gov. uk/government/publications/uk-physical-activity-guidelines (accessed on 22 June 2019).

27. Alonso-Domínguez, R.; Patino-Alonso, M.C.; Sánchez-Aguadero, N.; García-Ortiz, L.; Recio-Rodríguez, J.I.; Gómez-Marcos, M.A. Effect of a multifactorial intervention on the increase in physical activity in subjects with type 2 diabetes mellitus: A randomized clinical trial (EMID Study). Eur. J. Cardiovasc. Nurs. 2019, 18, 399-409. [CrossRef] [PubMed]

28. Kakamu, T.; Hidaka, T.; Kumagai, T.; Masuishi, Y.; Kasuga, H.; Endo, S.; Sato, S.; Takeda, A.; Koizumi, M.; Fukushima, T. Unhealthy changes in eating habits cause acute onset hypertension in the normotensive community-dwelling elderly-3 years cohort study. Medicine 2019, 98, e15071. [CrossRef] [PubMed]

29. Arija, V.; Villalobos, F.; Pedret, R.; Vinuesa, A.; Timón, M.; Basora, T.; Aguas, D.; Basora, J. Effectiveness of a physical activity program on cardiovascular disease risk in adult primary health-care users: The "Pas-a-Pas" community intervention trial. BMC Public Health 2017, 17, 1-11. [CrossRef] [PubMed]

30. Stalsberg, R.; Pedersen, A.V. Are Differences in Physical Activity across Socioeconomic Groups Associated with Choice of Physical Activity Variables to Report? Int. J. Environ. Res. Public Health 2018, 15, 922. [CrossRef] [PubMed]

31. Manz, K.; Mensink, G.B.M.; Jordan, S.; Schienkiewitz, A.; Krug, S.; Finger, J.D. Predictors of physical activity among older adults in Germany: A nationwide cohort study. BMJ Open 2018, 8, 1-10. [CrossRef] [PubMed]

32. O'Donoghue, G.; Kennedy, A.; Puggina, A.; Aleksovska, K.; Buck, C.; Burns, C.; Cardon, G.; Carlin, A.; Ciarapica, D.; Colotto, M.; et al. Socio-economic determinants of physical activity across the life course: A “DEterminants of DIet and Physical ACtivity" (DEDIPAC) umbrella literature review. PLoS ONE 2018, 13, 1-24. [CrossRef]

33. LeBouthillier, D.M.; Thibodeau, M.A.; Asmundson, G.J.G. Severity of Fall-Based Injuries, Fear of Falling, and Activity Restriction: Sex Differences in a Population-Based Sample of Older Canadian Adults. J. Aging Health 2013, 25, 1378-1387. [CrossRef] 
34. Finlayson, M.L.; Peterson, E.W. Falls, aging, and disability. Phys. Med. Rehabil. Clin. N. Am. 2010, 21, 357-373. [CrossRef]

35. Stahl, S.T.; Albert, S.M. Gender differences in physical activity patterns among older adults who fall. Prev. Med. 2015, 71, 94-100. [CrossRef]

36. Moschny, A.; Platen, P.; Klaaßen-Mielke, R.; Trampisch, U.; Hinrichs, T. Physical activity patterns in older men and women in Germany: A cross-sectional study. BMC Public Health 2011, 11, 559. [CrossRef] [PubMed]

37. Li, W.; Procter-Gray, E.; Churchill, L.; Crouter, S.E.; Kane, K.; Cheng, J.; Rui, F.; Tian, J.; Franklin, P.D.; Ockene, J.K.; et al. Gender and age differences in levels, types and locations of physical activity among older adults living in car-dependent neighborhoods. J. Frailty Aging 2017, 6, 129-135. [PubMed]

38. Swan, J.H.; Brooks, J.M.; Amini, R.; Moore, A.R.; Turner, K.W. Smoking Predicting Physical Activity in an Aging America. J. Nutr. Health Aging 2018, 22, 476-482. [CrossRef] [PubMed]

39. Heydari, G.; Hosseini, M.; Yousefifard, M.; Asady, H.; Baikpour, M.; Barat, A. Smoking and Physical Activity in Healthy Adults: A Cross-Sectional Study in Tehran. Tanaffos 2015, 14, 238-245. [PubMed]

40. Koolhaas, C.M.; Dhana, K.; Schoufour, J.D.; Ikram, M.A.; Kavousi, M.; Franco, O.H. Impact of physical activity on the association of overweight and obesity with cardiovascular disease: The Rotterdam Study. Eur. J. Prev. Cardiol. 2017, 24, 933-940. [CrossRef]

41. Cárdenas Fuentes, G.; Bawaked, R.A.; Martínez González, M.Á.; Corella, D.; Subirana Cachinero, I.; Salas-Salvadó,J.; Estruch, R.; Serra-Majem, L.; Ros, E.; Lapetra Peralta, J.; et al. Association of physical activity with body mass index, waist circumference and incidence of obesity in older adults. Eur. J. Public Health 2018, 28, 944-950. [CrossRef]

42. Watson, K.B.; Carlson, S.A.; Gunn, J.P.; Galuska, D.A.; O'Connor, A.; Greenlund, K.J.; Fulton, J.E. Physical Inactivity Among Adults Aged 50 Years and Older-United States, 2014. Morb. Mortal. Wkly. Rep. 2016, 65, 954-958. [CrossRef] [PubMed]

43. Doubova, S.V.; Sánchez-García, S.; Infante-Castañeda, C.; Pérez-Cuevas, R. Factors associated with regular physical exercise and consumption of fruits and vegetables among Mexican older adults. BMC Public Health 2016, 16, 1-9. [CrossRef]

44. Södergren, M.; McNaughton, S.A.; Salmon, J.; Ball, K.; Crawford, D.A. Associations between fruit and vegetable intake, leisure-time physical activity, sitting time and self-rated health among older adults: Cross-sectional data from the WELL study. BMC Public Health 2012, 12, 1-9. [CrossRef]

45. Bae, W.; Ik Suh, Y.; Ryu, J.; Heo, J. Physical Activity Levels and Well-Being in Older Adults. Psychol. Rep. 2017, 120, 192-205. [CrossRef]

46. Hassmén, P.; Koivula, N.; Uutela, A. Physical Exercise and Psychological Well-Being: A Population Study in Finland. Prev. Med. 2000, 30, 17-25. [CrossRef] [PubMed]

47. Black, S.V.; Cooper, R.; Martin, K.R.; Brage, S.; Kuh, D.; Stafford, M. Physical Activity and Mental Well-being in a Cohort Aged 60-64 Years. Am. J. Prev. Med. 2015, 49, 172-180. [CrossRef] [PubMed]

48. Parra-Rizo, M.A. Impact of Physical Activity on the Psychological Health of the Elderly. Psychol. Behav. Sci. 2018, 7, 77-81. [CrossRef]

49. Parra-Rizo, M.A. Componentes de influencia más valorados en la calidad de vida por las personas mayores de 60 años físicamente activas. Eur. J. Investig. Health Psychol. Educ. 2017, 7, 135. [CrossRef]

50. Hsu, C.L.; Best, J.R.; Davis, J.C.; Nagamatsu, L.S.; Wang, S.; Boyd, L.A.; Hsiung, G.R.; Voss, M.W.; Eng, J.J.; Liu-Ambrose, T. Aerobic exercise promotes executive functions and impacts functional neural activity among older adults with vascular cognitive impairment. Br. J. Sports Med. 2018, 52, 184-191. [CrossRef] [PubMed]

(C) 2019 by the authors. Licensee MDPI, Basel, Switzerland. This article is an open access article distributed under the terms and conditions of the Creative Commons Attribution (CC BY) license (http://creativecommons.org/licenses/by/4.0/). 